\title{
Development of a seedling tray seeder for lettuce (Lactuca sativa L.) production
}

\author{
Coleman Tiw-an ${ }^{1 *}$, Romeo Gavino ${ }^{1}$, Helen Gavino ${ }^{1}$, and Jeffrey Lavarias ${ }^{1}$ \\ ${ }^{1}$ Central Luzon State University, Department of Agricultural and Biosystems Engineering, Science \\ City of Muñoz, Nueva Ecija, Philippines
}

\begin{abstract}
Conventional method of sowing lettuce is laborious and time consuming. Thus, this study was conducted to develop a seedling tray seeder for lettuce. Specifically, it aimed to design a seeder, fabricate the design, evaluate the field performance parameters, and analyze the cost of operation of using the machine. The machine was fabricated based on the design plan which was comprised of the dibbler unit, seed metering unit, soil covering unit, power transmission system, automation unit and frame assembly. Performance evaluation of the device was undertaken both in the laboratory and in the field. The cost of using the machine was analyzed considering the best operating parameters. Machine parameters such a vacuum pressure at $1.35-2.03 \mathrm{kPa}, 2.04-2.70 \mathrm{kPa}$, and $2.71-3.39 \mathrm{kPa}$ were evaluated to determine the optimum capacity and seeder efficiency. Results revealed the machine has a capacity of 26 trays per hour at $2.04-2.70 \mathrm{kPa}$ vacuum pressure with a seeder efficiency of $93.75 \%$. The overall cost of fabricating the device was Php83,476.00. The cost analysis revealed that the break-even point is at 7,547 trays per year and an income of Php119,059.00 per annum can be realized with a payback period at 0.7 years.
\end{abstract}

\section{Introduction}

Lettuce (Lactuca sativa L.) is an annual plant that is often grown as leaf vegetable, but sometimes for its stem and seeds. On an average, a farmer can obtain head lettuce about 11,000 to $12,000 \mathrm{~kg} / \mathrm{ha}$ of land. Crop Statistics of the Philippines 2018 [1] quantified that production of lettuce in the country reached 4,083 MT. Cordillera Administrative Region (CAR) and Northern Mindanao are the top producers in the Philippines with 1,099 MT and $1,728 \mathrm{MT}$, respectively. The labor requirement of each field operation in lettuce cultivation for a 1-ha land area with seedling preparation, land preparation, crop establishment/ transplanting, crop care and maintenance, and harvesting at 18 man-days, 50 man-days, 40 man-days, 80 man-days, and 20 man-days, respectively [2]. In cultivating lettuce, seedlings are

\footnotetext{
* Corresponding author: coleman.tiw.an@gmail.com
} 
grown in seedling trays and then transplanted in a well- prepared bed in the field or in greenhouses. The current practice of sowing the lettuce seeds in seedling trays, however, is a very tedious job. It is laborious and time consuming thus requiring physical capacity to work. Farmers do manual sowing of lettuce in trays with a capacity of 8 trays per hour. Moreover, a 10-gram pack of seeds is costly at 850.00 peso per pack. With the average area of 0.25 ha planted by a farmer, 350 trays (128 cells) is needed. Hence, for seedling production alone, a farmer needed 43.75 man-hours to sow the seeds in the tray and about 5 packs of lettuce seeds. The slow and laborious conventional sowing of lettuce limits the seedling production capacity of farmers and nursery growers in the locality. Subsequently, delay in planting period affects the production for the market. Wastage of expensive seeds is an additional burden to the stakeholders. While there are existing precision seeders abroad, these are costly which do not fit the financial capacity of the farmers including problems on after sales maintenance of the machine, hence, developing a locally-made seeder for lettuce seeds was deemed necessary in this study.

The general objective of the study was to develop a seedling tray seeder for the production of lettuce seedlings. Specifically, the study aimed to:

1. design a seedling tray seeder for lettuce;

2. fabricate the designed tray seeder;

3. evaluate the field performance of the machine; and,

4. analyze the cost of operations using the machine.

\section{Materials and methods}

\subsection{Design of the tray seeder}

The machine was designed for lettuce seedling production inside nurseries. The design plan of the device was based on the benchmarking of the conventional practices of sowing lettuce seeds and from literatures for precision tray seeders. The current practices and preferences of the farmers were considered while the machine components and standards were from literature. The initial design concept was then used in the design calculations, identification and selection of materials, component specification and the design plan used in the fabrication of the device. The design considerations were based on crop requirements and the conventional way of lettuce production. These include the ability of the machine to sow 1-2 lettuce seeds per cell, perform sowing of seeds with at least 24 trays per hour capacity, and at least $90 \%$ seeding efficiency.

\subsection{Fabrication of the tray seeder}

Fabrication of the machine was carried out after the design plan was approved. The materials and components used were based on the specifications set in the design plan. The machine was fabricated using simple and local manufacturing tools and equipment. Locally available materials and components such as mild steel plate, flat bar, angle bar, round bar, fiber glass, cold-rolled steel, pipe and rod were used during the fabrication process. 


\subsection{Evaluation of the performance of the machine}

The device was tested in the laboratory in order to establish the treatments, examine the performance of dibbling depth and metering mechanism. During the test, the seedling trays were manually filled with soil and compost mixture. The machine was stopped after the tray passed through the dibbler unit. The dibbling depth were measured to check the uniformity.

Field testing was done to obtain actual data on overall machine performance. The machine was evaluated to determine the effects of different vacuum pressure at P1 (1.35 - 2.03 $\mathrm{kPa})$, P2 (2.04 - 2.70 kPa), and P3 $2.71-3.39 \mathrm{kPa})$ on the capacity, seeding efficiency, and seeding conformity. Moreover, the optimum vacuum pressure during of the device were used to compare with conventional method of sowing lettuce seeds. The number seeds sown per cell were estimated using the number of seeds germinated as shown in Equation 4.

Seeder Capacity (C). The measure of the machine's ability to do a job under actual field conditions. It is determined in terms of the number of trays sown per hour.

$$
C=\text { number of trays seeded time spent in seeding the tray }
$$

Seeder Efficiency (Effs). The total percentage of cells seeded in tray.

$$
\text { Effs }=(\text { number of cells Seeded total cells of the tray) } x 100
$$

Seeder Conformity (Conformity). The total percentage of cells seeded in tray with $1-2$ seeds.

Conformity $=($ number of cells seeded with 1-2 seeds total cells of the tray) $x 100$

Number of Seeds Sown (Seeds Sown). The number of seeds sown per cell is estimated by counting the number of seeds germinated.

Seeds Sown = number of seeds germinated $/$ germination rate

The effect of the three different vacuum pressures with three replications on sowing time and the number of seeds deposited per cell were further analyzed through Completely Randomized Design (CRD) and Least Significant Difference (LSD) at 5\% level of significance.

\subsection{Cost analysis of the device}

A simple cost analysis was done to evaluate the financial and economic analysis of the tray seeder. Other than the capacity and conformity of a machine, clients usually consider the economic viability before investing on it. The equations used to determine the break-even point, net income, and payback period were from [3]. 


\section{Results and discussion}

\subsection{Design plan of the machine}

The design plan of the machine is presented in Figure 1. The size of the machine elements was computed but their specifications were adjusted depending on the materials available in the market. The major components of the machine include the (1) dibbler unit, (2) seed metering unit, (3) soil covering unit, (4) transmission unit, (5) automation unit, and (6) main frame unit.

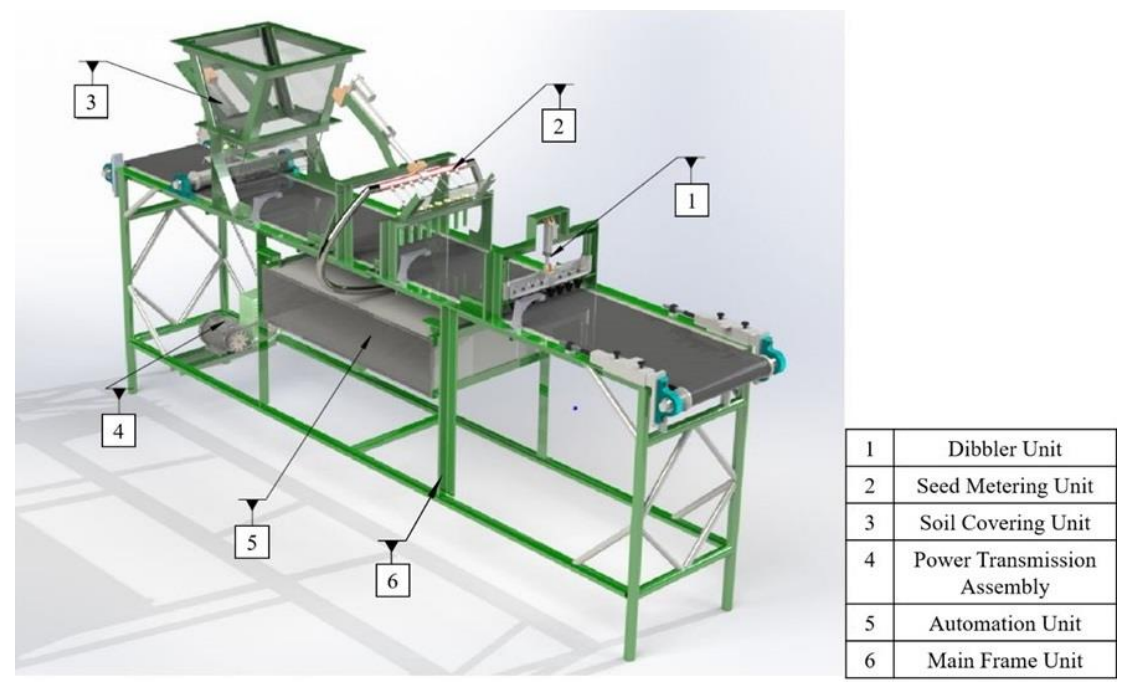

Fig. 1. Isometric view of the seedling tray seeder.

\subsection{Fabrication of the tray seeder}

The machine was fabricated in La Trinidad, Benguet. After the fabrication and assembly of the different components, the tray seeder, shown on Figure 2, is a machine that can sow lettuce seeds in a seedling tray. The device can make pits on the soil, deposit and cover $1-2$ seeds per cell. It is portable and a self-propelled machine which can be operated by a $1-2$ individuals. This was designed using locally available materials and was fabricated adopting local manufacturing technology thus, making it affordable. 


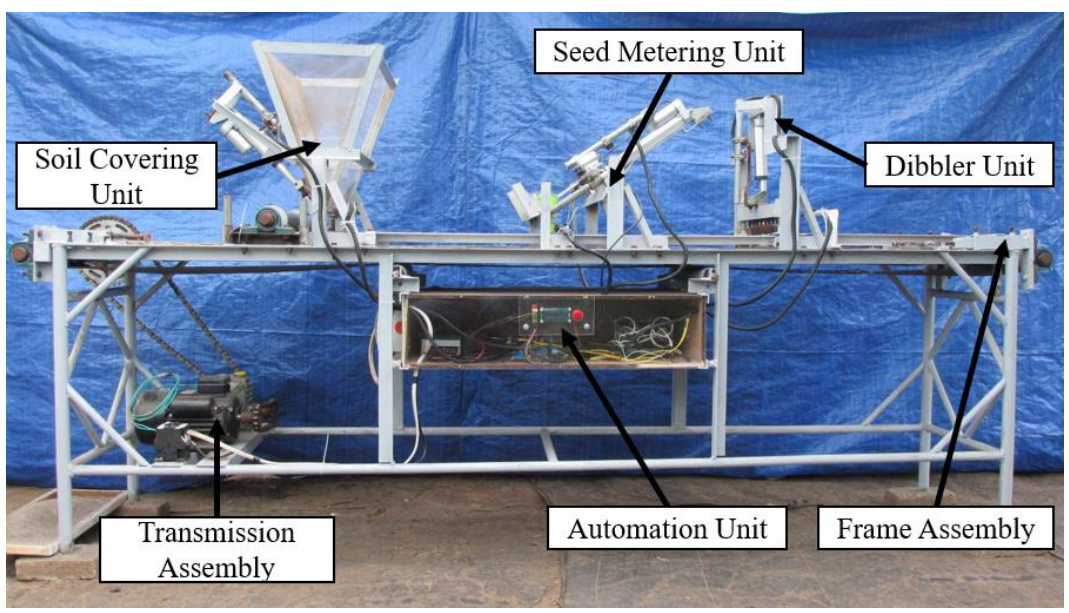

Fig. 2. The seedling tray seeder.

\subsection{Performance of the machine}

\subsubsection{Machine capacity}

The capacity of the machine in sowing lettuce seeds was computed using Equation 1. For all treatments, the seeder capacity was the same at 26 trays per hour since the seeder capacity was focused on the vacuum pressure applied to seed metering mechanisms. The speed of travel of the seedling tray from dibbling to seed covering were the same (135 seconds) during the whole process, hence, seeder capacity was the same at 26 trays per hour.

\subsubsection{Seeder efficiency}

The ability of the seeder to place seeds into each cell of the tray was determined through the seeder efficiency. Table 1 gives the seeder efficiency, i.e., percent of cells with lettuce seeds sown, of the machine as affected by three vacuum pressures. Seeder efficiency was highest $(93.75 \%)$ at $2.04-2.70 \mathrm{kPa}$ vacuum pressure followed by $83.33 \%$ and $78.47 \%$ for pressures at $2.71-3.39 \mathrm{kPa}$ and $1.35-2.03 \mathrm{kPa}$, respectively.

Analysis of variance revealed highly significant effect of the vacuum pressure on the seeding efficiency. The mean seeding efficiency for each vacuum pressure setting were compared to each other and as indicated in Table 3, the highest seeding efficiency $(93.75 \%)$ observed at the $2.04-2.70 \mathrm{kPa}$ pressure was significantly better than the $83.33 \%$ and $78.47 \%$ seeding efficiencies attained at $2.71-3.39 \mathrm{kPa}$ and $1.35-2.03 \mathrm{kPa}$ vacuum pressures, respectively. It should be noted also that only the $93.75 \%$ seeding efficiency surpassed the $90 \%$ design requirement. It was observed that with high vacuum pressure, the needle draws multiple number of seeds while the missing hills were caused by high suction that tends to hold the seeds instead of dropping. At lowest vacuum pressure, the suction is low that the needles missed to regularly draw seeds from the hopper. 
Table 1. Seeder efficiency of the machine as affected by the vacuum pressure.

\begin{tabular}{|c|c|}
\hline Treatment (vacuum pressure) & Seeder efficiency* (\%) \\
\hline $\mathrm{P}_{1}(1.35-2.03 \mathrm{kPa})$ & $78.47^{\mathrm{c}}$ \\
$\mathrm{P}_{2}(2.04-2.70 \mathrm{kPa})$ & $93.75^{\mathrm{a}}$ \\
$\mathrm{P}_{3}(2.71-3.39 \mathrm{kPa})$ & $83.33^{\mathrm{b}}$ \\
\hline
\end{tabular}

*Means side scored by the same letter are not significantly different at 5\% using LSD.

\subsubsection{Percentage of cells with germinated seeds}

After the field test, the lettuce seeds were allowed to germinate in order to see and count the number of germinated seeds in each cell of the tray. It should be noted also that the germination test in the laboratory revealed a $98 \%$ germination rate. Hence, in the counting of seeds that germinated, the $98 \%$ germination rate was considered.

\subsubsection{Percentage of cells with single germinated seed}

Table 2 shows the percentage of single germinated seed in the cells. It can be noted that at a vacuum pressure of $2.04-2.70 \mathrm{kPa}, 68.06 \%$ of the cells have one germinated seed, $56.94 \%$ was seen when vacuum pressure was at $1.35-2.03 \mathrm{kPa}$, and the lowest percentage $(40.97 \%)$ was observed at the highest pressure of $2.71-3.39 \mathrm{kPa}$.

Table 2. Seeder efficiency of the machine as affected by the vacuum pressure.

\begin{tabular}{|c|c|c|c|c|c|}
\hline \multirow{2}{*}{$\begin{array}{l}\text { Treatment } \\
\text { (vacuum } \\
\text { pressure) }\end{array}$} & \multicolumn{5}{|c|}{ Percentage of cells*, \% } \\
\hline & Single & Double & Conformed & Multiple & Missed \\
\hline $\begin{array}{c}\mathrm{P}_{1}(1.35- \\
2.03 \mathrm{kPa})\end{array}$ & $56.94^{\mathrm{b}}$ & 19.44 & $76.39^{b}$ & $2.08^{\mathrm{a}}$ & $21.53^{\mathrm{a}}$ \\
\hline $\begin{array}{c}\mathrm{P}_{2}(2.04 \text { - } \\
2.70 \mathrm{kPa})\end{array}$ & $68.06^{\mathrm{a}}$ & 22.22 & $90.28^{a}$ & $3.47^{\mathrm{a}}$ & $6.25^{\mathrm{c}}$ \\
\hline $\begin{array}{c}\mathrm{P}_{3}(2.71 \text { - } \\
3.39 \mathrm{kPa})\end{array}$ & $40.97^{c}$ & 30.56 & $71.53^{\mathrm{c}}$ & $11.81^{\mathrm{b}}$ & $16.67^{b}$ \\
\hline
\end{tabular}

*Means side scored by the same letter are not significantly different at $5 \%$ using LSD.

Analysis of variance revealed that the vacuum pressure significantly affected the percent single germinated seed in a cell. The comparison among means confirmed that all the mean percent single germinated seed in a cell were significantly different from each other. Similar trend of results was observed during the laboratory test, though the field test indicated lower percentages in every treatment which may possibly be attributed to the germination rate of the lettuce seeds. Another considerable reason is that the seeds might not have sprouted when the germinated seedlings were counted.

\subsubsection{Percentage of cells with two germinated seeds}

The percentage of two germinated seeds per cell is presented in Table 2. It was observed that the percent double germinated seeds in a cell increased as the vacuum pressure was increased. 
At the highest pressure $(2.71-3.39 \mathrm{kPa}), 30.56 \%$ of the cells had two germinated seeds. A minimal change from $22.22 \%$ to $19.44 \%$ at vacuum pressures $2.04-2.70 \mathrm{kPa}$ and $1.35-$ $2.03 \mathrm{kPa}$, respectively, were likewise noted.

The analysis of variance, however, showed that the different vacuum pressures did not affect significantly the percent double germinated seeds in a cell as sown by the machine. Probably, this can also be attributed to the germination rate of the seeds used in the test and the number of days after seeding when the germinated seeds were counted. It is still evident though, that more double germinated seeds were recorded at the highest vacuum pressure.

\subsubsection{Percentage of cells with 1.2 germinated cells}

The percent of cells with 1-2 germinated seeds at different vacuum pressures during sowing by the machine were presented in Table 2 . It must be remembered that the target number of seeds per cell in the design was 1-2 seeds, hence this section shows the conformity with the required number of seeds per cell. The percent of cells with 1-2 germinated seeds was best at $2.04-2.70$ vacuum pressure with $90.28 \%$. This is followed by $76.39 \%$ at the lowest vacuum pressure $(1.35-2.03 \mathrm{kPa})$, and the lowest percent of cells with $1-2$ germinated seeds at $71.23 \%$ was recorded at the highest vacuum pressure setting.

Analysis of variance showed that vacuum pressure exhibited significant effect on the percent of cells with 1-2 germinated seeds. Moreover, comparison of means revealed that the mean percent of cells with 1-2 germinated seeds at different vacuum pressure settings during the sowing operation by the machine were significantly different from each other. The conformity percentage with the target number of seeds per cell was distinct from each other with the best at $90.28 \%$ at vacuum pressure of $2.04-2.70 \mathrm{kPa}$. It was observed that the suction pressure must match the ability of the needles to draw seeds on the hopper. At low vacuum pressure, the needles cannot get enough seeds while more seeds were obtained at the highest pressure. The slightly lower values from the result of the laboratory test can be attributed to the germination rate of the seeds and the number of days after seeding when the germinated seeds were counted.

\subsubsection{Percentage of cells with multiple germinated seeds}

The percentage of multiple seeds sown per cell is presented in Table 2. It was observed that the percent multiple seeds in a cell increased as the vacuum pressure was increased. At the highest pressure $(2.71-3.39 \mathrm{kPa}), 11.81 \%$ of the cells had multiple germinated seeds. A minimal change from $2.08 \%$ to $3.47 \%$ at vacuum pressures $1.35-2.03 \mathrm{kPa}$ and $2.04-2.70$ $\mathrm{kPa}$, respectively, were observed.

The analysis of variance, showed that the vacuum pressure significantly affected the percent multiple germinated seeds in a cell as sown by the machine. The comparison among means, however, revealed that the two lowest vacuum pressure were comparable but were both significantly different from the highest pressure $(2.71-3.39 \mathrm{kPa})$ with $11.81 \%$ multiple seeds sown.

\subsubsection{Percentage of cells with missing germinated seed}

The effect of vacuum pressure applied to the metering mechanism of the machine on missing germinated seeds per cell were analysed and shown in Table 2. Based on result, the highest mean percentage $(21.53 \%)$ was attained at vacuum pressure of $1.35-2.03 \mathrm{kPa}$, followed by the vacuum pressure of $2.71-3.35 \mathrm{kPa}$ at $16.67 \%$, and the lowest from $6.25 \%$ at $2.04-2.70$ $\mathrm{kPa}$ vacuum pressure. 
Analysis of variance revealed a highly significant effect of the vacuum pressure on the percent missing germinated seeds per cells. Furthermore, comparison among means showed that the means of the cells with no germinated seeds were significantly different from each other with the best $(6.25 \%)$ at $2.04-2.70 \mathrm{kPa}$. It was noted that the dissimilarity of the result from the laboratory test may be due to germination rate and climate factors during the development of seeds.

\subsubsection{Mechanized sowing of lettuce}

Corresponding mean values on the comparison of machine and manual sowing of lettuce are presented on Table 3. Using 10 trays per method of sowing, results revealed that manual and machine sowing has a capacity of 8 and 26 trays per hour, respectively. Use of the machine tripled the capacity of manual sowing. The increase in capacity would also increase seedling production while reducing manual labor requirement. However, seeder efficiency is almost the same at $90.83 \%$ and $90.84 \%$ for machine and manual sowing, respectively. The standard deviation of the machine capacity is 0.18 for manual sowing while the machine has a constant capacity. On the other hand, standard deviation of field efficiency is 1.86 and 4.56 percent for manual and machine sowing, respectively.

Table 3. Seeder efficiency of the machine as affected by the vacuum pressure.

\begin{tabular}{|c|c|c|}
\hline Treatment & Capacity (tray/hr) & Seeding efficiency (\%) \\
\hline Machine & 26 & 90.83 \\
Manual & 8 & 90.84 \\
\hline
\end{tabular}

\subsubsection{Cost analysis on the use of the device}

The cost of the machine, which included the material and fabrication costs, amounted to Php $83,475.56$. The simple financial analysis of the device was performed considering some basic assumptions. The depreciation was determined using the straight line method with such other assumptions as: the device has a life span of five years; interest on investment of $15 \%$; and housing, taxes and insurance of $2.5 \%$. The machine was calculated to operate with a fixed annual cost of Php23,999.22 and a variable cost of Php94.81 per hour. Generally, cost of sowing decreases with the increase of number of trays sown per year. Using the machine for custom service operation and setting the custom rate at PhP6.83 per tray, the seeder has a break-even point of 7,547 trays per year. At the capacity of 37,440 trays per year, the net income that could be derived will be $\mathrm{PhP} 119,059$ per year. Hence, payback period to recover the cost of the machine was computed at 0.7 years.

\section{Conclusions}

Based on the results of the study, it can be concluded that:

1. the designed seedling tray seeder can make pits, deposit and cover $1-2$ lettuce seeds per cell of the tray. The major components of the design are dibbler unit, seed metering unit, soil covering unit, power transmission assembly, automation unit, and frame assembly;

2. the machine can be fabricated using locally available materials and can make a portable and self-propelled machine;

3. sowing lettuce seeds using the machine has a field efficiency of $93.75 \%$ at $2.04-2.70$ $\mathrm{kPa}$ vacuum pressure, thereby reducing the labor requirement on sowing lettuce. With an 8 tray/hr manual sowing capacity, the device significantly increased at 26 trays per hour; and, 
4. the investment cost of the machine is Php83,475.56 and an annual income of Php119,059.00. Further analysis showed that the machine has a break-even point at 7,547 trays per year and a payback period at 0.70 years.

The authors would like to acknowledge the Department of Science and Technology-Engineering Research and Development Technology (DOST-ERDT) for funding the research study and the Department of Agricultural and Biosystems Engineering, College of Engineering, Central Luzon State University for the guidance and technical assistance in the completion of this study.

\section{References}

1. C.D. Mapa, CSP, 96 (2019)

2. D. Jose, LPG, 9 (2018)

3. D. Hunt, Farm Power and Machinery Management, E 10, 77-88 (2001) 